Regular Article

pISSN: 2287-2396, eISSN: 2287-240X

Journal of Forest Science

Vol. 29, No. 3, pp. 211-218, August, 2013

http://dx.doi.org/10.7747/JFS.2013.29.3.211

\title{
Comparison of Ground Beetle Communities (Coleoptera: Carabidae) between Coniferous and Deciduous Forests in Agricultural Landscapes
}

\author{
Jong-Kook Jung ${ }^{1}$, Seung-Tae Kim, ${ }^{2,}$, Sue-Yeon Lee ${ }^{2}$, Jung-Sun Yoo ${ }^{3}$ and Joon-Ho Lee,2 \\ ${ }^{1}$ Entomology Program, Department of Agricultural Biotechnology, \\ ${ }^{2}$ Research Institute for Agriculture and Life Sciences, Seoul National University, Seoul 151-921, Republic of Korea \\ ${ }^{3}$ Department of Invertebrates, National Institute of Biological Resources, Incheon 404-170, Republic of Korea
}

\begin{abstract}
This study was conducted to examine the community structure of ground beetles between coniferous- and deciduous-dominant forest in agricultural landscapes, in Miryang-si, Yeongdong-gun, Icheon-si, and Cheolwon-gun during April to October in 2009. A total of 19 species belonging to 15 genera of 9 subfamilies were identified from 6,253 collected ground beetles. Dominant species from 4 regions were Synuchus nitidus (3,715 individuals, 59.4\% of total) and Synuchus cyloderus (1,783 individuals, $28.5 \%)$ respectively. Non-metric multidimensional scaling based on Bray-Curtis similarity showed that ground beetle assemblage was not different between forest stands, but it was significantly different among regions. Overall, forest stands of secondary forests may not show a different community structure of ground beetle assemblages in our study. However, monitoring on the ground beetle fauna as well as other arthropods of secondary forests in agricultural landscapes is still important for the management and conservation of biodiversity, because forests provides important habitats for many predatory arthropods, such as ground beetles, spiders and rove beetles.
\end{abstract}

Key Words: ground beetles, monitoring, biodiversity, conservation, forest stands

\section{Introduction}

Due to the increasing of disturbance followed by human activity, natural and semi-natural habitats have been continuously decreased in worldwide. Traditional agricultural landscapes are experiencing pressures from development and intensification (Katoh et al. 2009). Thus, the conservation of biodiversity is also one of the major concerns in these landscapes during environment change. In Korea, agricultural landscapes are composed of mosaic habitats such as forests (natural and artificial forest, coppice woodlands and grasslands), farmlands (rice and upland fields), settlements and reservoirs, and thus, biodiversity in agricultural landscapes is usually rich. The depopulation of rural society and the conversion of land-uses have caused the succession of forests in agricultural landscapes. In particular, land conversions are leading to a loss of biodiversity because of the decrease of heterogeneity (Choi et al. 2009).

Most studies about biodiversity and conservation in Korea have been focused on mountains, especially well con-

Received: July 3, 2013. Revised: August 12, 2013. Accepted: August 14, 2013.

Corresponding author: Seung-Tae Kim

Research Institute for Agriculture and Life Sciences, Seoul National University, Seoul 151-921, Republic of Korea

Tel: 82-2-880-4692, Fax: 82-2-873-2319, E-mail: stkim2000@hanmail.net 
served areas, but secondary forests in agricultural landscapes have been neglected during past decades (Choi et al. 2009). Takeuchi et al. (2003) pointed out that conservation of agricultural forests and its landscapes are important to maintain the biodiversity such as mammals, birds and arthropods, because these forests provide temporary refuges, habitats of reproduction, and overwintering sites for predatory invertebrates including ground beetles (Sotherton 1985; Wallin 1986; Thomas et al. 1991; Kagawa and

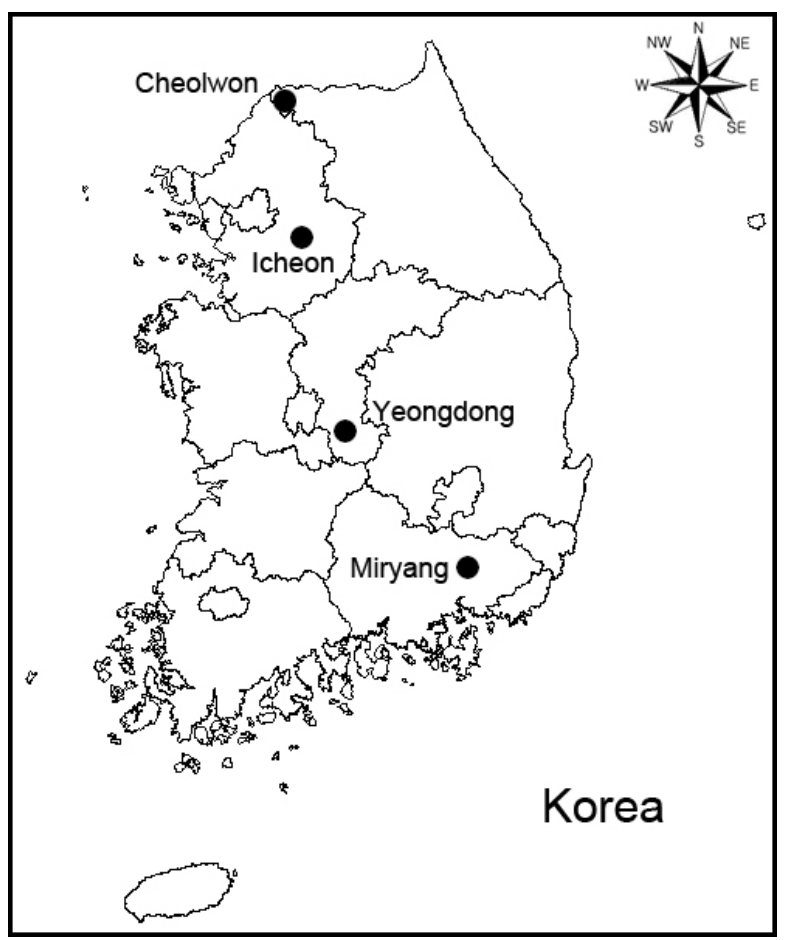

Fig. 1. Locations of 4 study regions.
Maeto 2009). In addition, many predatory invertebrates are needed various habitats including secondary forests for complete of their life cycle (Kagawa and Maeto 2009).

Ground beetles are important in the agricultural ecosystem generally, because they feed on many invertebrate pests such as aphids, snails, lepidopteran larvae and so on (Lövei and Sunderland 1996; Kromp 1999; Holland 2002). In addition, many studies showed that ground beetles can be used a bioindicator for assessing the environmental status (Rainio and Niemelä 2003; Pearce and Venier 2006), because they adapt to certain habitats and many factors can affect to their distributions generally. Thus, to investigate the ground beetles in agricultural ecosystems will be important for the managements of semi-natural habitat and biodiversity.

This study was conducted to examine the community structure of ground beetles between coniferous and deciduous forests in agricultural landscapes along latitudinal gradient in Miryang-si, Yeongdong-gun, Icheon-si, and Cheolwon-gun, Korea.

\section{Materials and Methods}

\section{Study areas and its environmental variables}

Study sites were selected along latitudinal gradient as surrogate for annual mean temperature (Fig. 1, Table 1). Each study sites were composed of 2 forest stands between coniferous and deciduous forests. Descriptions of each sampling site were showed in Table 2. In general, forests in the rural landscapes of Korea are composed of Pinus densi-

Table 1. Habitat environments in each investigated rural forest

\begin{tabular}{|c|c|c|c|c|c|c|c|}
\hline \multirow{2}{*}{ Region } & \multirow{2}{*}{ Stand } & \multicolumn{6}{|c|}{ Environmental variable (mean $\pm \mathrm{SE}$ ) } \\
\hline & & Temp. $\left({ }^{\circ} \mathrm{C}\right)$ & S.T. $\left({ }^{\circ} \mathrm{C}\right)$ & R.H. (\%) & S.H. (\%) & L. $(\mathrm{cm})$ & I. $\left({ }^{\circ}\right)$ \\
\hline \multirow[t]{2}{*}{ Miryang-si, Gyeongsangnam-do } & Coniferous & $24.1 \pm 0.9$ & $18.6 \pm 1.0$ & $53.9 \pm 5.2$ & $10.9 \pm 2.0$ & $4.1 \pm 0.2$ & $16.7 \pm 2.6$ \\
\hline & Deciduous & $23.4 \pm 1.0$ & $16.6 \pm 1.2$ & $54.6 \pm 4.5$ & $26.1 \pm 2.7$ & $5.4 \pm 0.3$ & $18.5 \pm 2.4$ \\
\hline \multirow[t]{2}{*}{ Yeongdong-gun, Chungcheongbuk-do } & Coniferous & $24.6 \pm 0.6$ & $16.9 \pm 1.2$ & $49.5 \pm 4.1$ & $16.4 \pm 2.2$ & $5.5 \pm 0.3$ & $18.3 \pm 1.2$ \\
\hline & Deciduous & $24.5 \pm 0.9$ & $15.9 \pm 1.2$ & $48.5 \pm 4.1$ & $24.8 \pm 2.9$ & $5.8 \pm 0.6$ & $16.8 \pm 1.9$ \\
\hline \multirow[t]{2}{*}{ Icheon-si, Gyeonggi-do } & Coniferous & $24.0 \pm 0.9$ & $15.5 \pm 1.2$ & $46.3 \pm 3.1$ & $18.3 \pm 2.0$ & $5.7 \pm 0.4$ & $12.6 \pm 1.0$ \\
\hline & Deciduous & $24.3 \pm 0.8$ & $15.3 \pm 1.3$ & $48.8 \pm 3.6$ & $34.3 \pm 2.8$ & $5.4 \pm 0.5$ & $10.4 \pm 1.0$ \\
\hline \multirow[t]{2}{*}{ Cheolwon-gun, Gangwon-do } & Coniferous & $22.0 \pm 1.5$ & $13.5 \pm 1.6$ & $54.0 \pm 2.9$ & $24.3 \pm 2.8$ & $5.7 \pm 0.4$ & $16.6 \pm 1.6$ \\
\hline & Deciduous & $23.4 \pm 1.1$ & $13.2 \pm 1.6$ & $53.1 \pm 3.8$ & $22.7 \pm 2.3$ & $5.8 \pm 0.5$ & $21.2 \pm 1.4$ \\
\hline
\end{tabular}

Temp., temperature; S.T., soil temperature; R.H., air relative humidity; S.H., soil humidity; L., leaf litter depth; I., incline. 
Jung et al.

Table 2. Habitat environments, coordinates and altitudes of each investigated location

\begin{tabular}{|c|c|c|c|c|c|c|}
\hline Location & Abbreviation & Stand and environment & Dominant tree & Longitude & Latitude & Altitude (m) \\
\hline \multirow[t]{2}{*}{$\begin{array}{l}\text { Miryang-si, } \\
\text { Gyeongsangnam-do }\end{array}$} & $\mathrm{MC}$ & $\begin{array}{l}\text { Coniferous forest adjacent } \\
\text { to paddy field and } \\
\text { residential area }\end{array}$ & Pinus densiflora & $128^{\circ} 49^{\prime} 43.8^{\prime \prime}$ & $35^{\circ} 30^{\prime} 04.4^{\prime \prime}$ & 55 \\
\hline & MD & $\begin{array}{l}\text { Deciduous forest adjacent } \\
\text { to river }\end{array}$ & $\begin{array}{l}\text { Castanea crenata } \\
\text { var.dulcis }\end{array}$ & $128^{\circ} 50^{\prime} 34.3^{\prime \prime}$ & $35^{\circ} 30^{\prime} 15.0^{\prime \prime}$ & 65 \\
\hline \multirow[t]{2}{*}{$\begin{array}{l}\text { Yeongdong-gun, } \\
\text { Chungcheongbuk-do }\end{array}$} & $\mathrm{YC}$ & $\begin{array}{l}\text { Coniferous forest adjacent } \\
\text { to vineyard }\end{array}$ & Pinus rigida & $127^{\circ} 52^{\prime} 16.4^{\prime \prime}$ & $36^{\circ} 11^{\prime} 44.8^{\prime \prime}$ & 205 \\
\hline & YD & $\begin{array}{l}\text { Deciduous forest adjacent } \\
\text { to vineyard }\end{array}$ & $\begin{array}{l}\text { Quercus acutissima } \\
\text { Castanea crenata } \\
\text { var.dulcis }\end{array}$ & $127^{\circ} 52^{\prime} 15.4^{\prime \prime}$ & $36^{\circ} 11^{\prime} 58.4^{\prime \prime}$ & 200 \\
\hline \multirow[t]{2}{*}{ Icheon-si, Gyeonggi-do } & IC & $\begin{array}{l}\text { Coniferous forest adjacent } \\
\text { to upland }\end{array}$ & Pinus rigida & $127^{\circ} 26^{\prime} 44.6^{\prime \prime}$ & $37^{\circ} 16^{\prime} 05.5^{\prime \prime}$ & 95 \\
\hline & ID & $\begin{array}{l}\text { Deciduous forest adjacent } \\
\text { to paddy field and } \\
\text { residential area }\end{array}$ & Quercus acutissima & $127^{\circ} 26^{\prime} 39.0^{\prime \prime}$ & $37^{\circ} 15^{\prime} 51.3^{\prime \prime}$ & 70 \\
\hline \multirow[t]{2}{*}{$\begin{array}{l}\text { Cheolwon-gun, } \\
\text { Gangwon-do }\end{array}$} & $\mathrm{CC}$ & $\begin{array}{l}\text { Coniferous forest adjacent } \\
\text { to paddy field }\end{array}$ & Pinus densiflora & $127^{\circ} 14^{\prime} 00.5^{\prime \prime}$ & $38^{\circ} 10^{\prime} 45.4^{\prime \prime}$ & 196 \\
\hline & $\mathrm{CD}$ & $\begin{array}{l}\text { Deciduous forest adjacent } \\
\text { to upland }\end{array}$ & Populus davidiana & $127^{\circ} 13^{\prime} 52.0^{\prime \prime}$ & $38^{\circ} 10^{\prime} 28.7^{\prime \prime}$ & 220 \\
\hline
\end{tabular}

flora Sieb. et Zucc., Pinus rigida Mill., Quercus spp. and Robinia pseudoacacia L. (Hong 1999). In particular, P. rigida and $R$. pseudoacacia are known to be introduced plants from North America for Forest Greenification in the past (Hong 1999). These trees are also dominant in our study sites generally.

Six environmental variables were measured in order to obtain the information of habitat conditions, such as air temperature and air relative humidity, soil temperature, soil humidity, leaf litter depth and incline (Table 2). Air and soil temperature, air and soil relative humidity were measured monthly on the afternoon of a typical sunny day around each pitfall trap within radius $5 \mathrm{~m}$.

\section{Sampling and identification}

Ground beetles were collected by pitfall traps during April to October in 2009. Three pitfall traps were installed $10 \mathrm{~m}$ apart from each other and were emptied every month. A pitfall trap was composed of a plastic container $(10.5 \mathrm{~cm}$ diameter and $8 \mathrm{~cm}$ depth) and a lid with 6 holes $(2 \mathrm{~cm}$ diameter in each hole) which prevents collecting unwanted small mammals. A plastic roof was set up to prevent rainfall. Traps were filled with preservative (95\% ethyl-al- cohol:95\% ethylene-glycol=1:1) for sample preservation. Collected ground beetles were brought to the laboratory and were dried, mounted, and identified to the species level under a dissecting microscope. Identification was performed according to $\mathrm{Habu}$ (1967, 1973, 1978, 1987), Kwon and Lee (1984), and Park and Paik (2001) and compared to voucher specimens in the laboratory. Nomenclature was confirmed by Park and Paik (2001) and Park (2004). Voucher specimens were stored in the insect ecology laboratory, Seoul National University.

\section{Data analyses}

Abundance and species richness were measured based on the number of individuals, and number of species collected in each sampling site, respectively. We pooled the data of collected ground beetles in each site and used in statistical analysis. For analysis of the species composition of the ground beetles among sites, a non-metric multidimensional scaling (MDS) with Bray-Curtis similarity was conducted using the PRIMER 6.0 (Clarke and Warwick 2001; Clarke and Gorley 2006). MDS was chosen because it performs well with ecological data that do not meet the assumption of normality (McCune and Grace 2002). Thus, 
Table 3. List of ground beetles in rural landscape between coniferous and hardwood forests

\begin{tabular}{|c|c|c|c|c|c|c|c|c|c|}
\hline \multirow{2}{*}{ Subfamily } & \multirow{2}{*}{ Scientific name } & \multicolumn{4}{|c|}{ Coniferous forest } & \multicolumn{4}{|c|}{ Deciduous forest } \\
\hline & & $\mathrm{MC}$ & $\mathrm{YC}$ & IC & $\mathrm{CC}$ & MD & YD & ID & $\mathrm{CD}$ \\
\hline \multirow[t]{3}{*}{ Carabinae } & Aulonocarabus koreanus koreanus & & & & & & & 42 & \\
\hline & Coptolabrus jankorwskii jankorwskii & & 1 & & & & & 10 & \\
\hline & Coptolabrus smaragdinus branickii & 7 & 9 & & 1 & 1 & 1 & & \\
\hline Nebriinae & Nebria chinensis chinensis & & & & & & & 1 & \\
\hline \multirow[t]{5}{*}{ Pterostichinae } & Pristosia vigil & & & & & & 1 & & \\
\hline & Synuchus cycloderus & & 823 & 177 & 92 & 1 & 410 & 196 & 84 \\
\hline & Synuchus nitidus & & 1,161 & 53 & 136 & 32 & 1,525 & 603 & 205 \\
\hline & Synuchus sp.1 & 2 & 286 & 67 & 36 & & 132 & 91 & 30 \\
\hline & Trigonognatha coreana & & 1 & 3 & & & & 2 & \\
\hline \multirow[t]{2}{*}{ Harpalinae } & Bradycellus sp.1 & & 1 & & & & & & \\
\hline & Harpalus discrepans & & & 1 & & & & 1 & \\
\hline Zabrinae & Amara sp.1 & & & 1 & & & & & \\
\hline \multirow[t]{2}{*}{ Callistinae } & Chlaenius naeviger & & 1 & 8 & 3 & & 1 & 2 & 1 \\
\hline & Chlaenius pallipes & & & 1 & & & & & \\
\hline Licininae & Diplocheila zeelandica & & & & & 5 & & & \\
\hline \multirow[t]{3}{*}{ Lebiinae } & Calleida onoha & & & & 1 & & & & \\
\hline & Dolichoctis luctuosus & & & & & & & & 1 \\
\hline & Galerita orientalis & 1 & & & & 1 & & & \\
\hline Brachininae & Brachinus stenoderus & & 1 & & & & & & \\
\hline Number of species & & 3 & 9 & 8 & 6 & 5 & 6 & 9 & 5 \\
\hline Number of individuals & & 10 & 2,284 & 311 & 269 & 40 & 2,070 & 948 & 321 \\
\hline
\end{tabular}

Abbreviated study site are: MC, YC, IC and CC are coniferous forests in Miryang-si, Yeongdong-gun, Icheon-si and Cheolwon-gun, respectively; MD, YD, ID and CD are deciduous forests in Miryang-si, Yeongdong-gun, Icheon-si and Cheolwon-gun, respectively.

MDS are the most generally effective ordination and classification methods for ecological community data (McCune and Grace 2002). In the MDS, the stress is a measure of distortion between the positions of real data points from the graphical representation. Thus, low stress represents few distortions from the real position of the data points and is associated with a graph that more accurately represents the dissimilarities in species composition. Group averaging cluster analysis was also performed for determining characteristics of groups. The one-way ANOSIM permutation test with a maximum of 999 permutations was used to assess the significant differences among land-use types in the MDS, and then Global $\mathrm{R}$ value approaches 1 if differences among land-use types exist (Clarke and Warwick 2001).

\section{Results}

A total of 19 species belonging to 9 subfamilies were identified from 6,253 collected ground beetles (Table 3). Pterostichinae was dominant and diverse subfamily in all sampling sites except on coniferous forest in Miryang-si (MC) (Table 3). The dominant species of all sampling sites were Synuchus nitidus (3,715 individuals, 59.4\% of total abundance) and Synuchus cycloderus (1,783 individuals, 28.5\%) (Fig. 2). Two dominant species, S. nitidus and S. cycloderus, showed two peaks in seasonal activity and showed a similar pattern between stands and among regions generally (Fig. 3), while the seasonal activity of S. nitidus in coniferous forest in Cheolwon-gun (CC) seems likely a peak (Fig. 3D).

Some large-sized ground beetles as Carabinae species were collected (Table 3). Coptolabrus smaragdimus branickii was mainly collected from coniferous forests in both Miryang-si (MC) and Yeongdong-gun (YC), while Coptolabrus jankoroskii jankorwskii was mainly collected from deciduous forest in Icheon-si (ID). In particular, Aulonocara- 

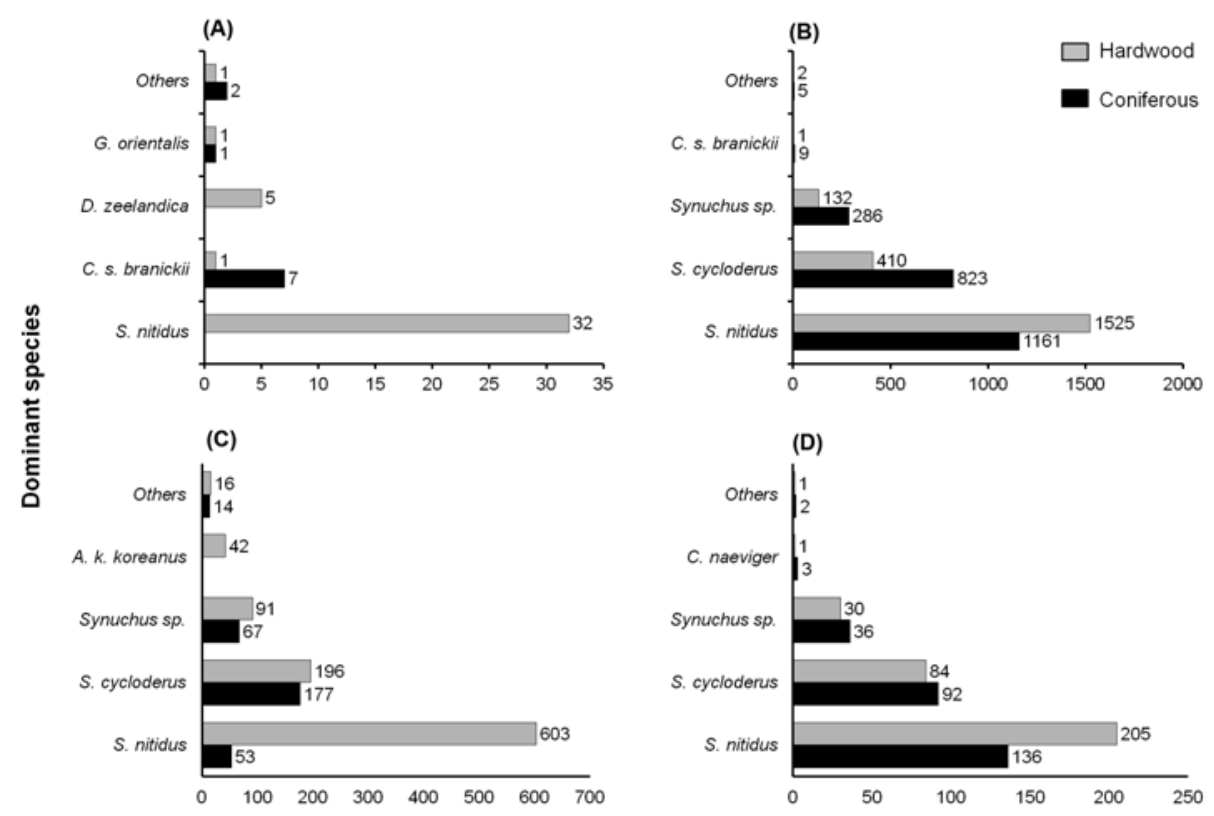

Abundance

Fig. 2. Dominant species between rural coniferous and deciduous forests in Miryang-si (A), Yeongdong-gun (B), Icheon-si (C) and Cheolwon-gun (D).
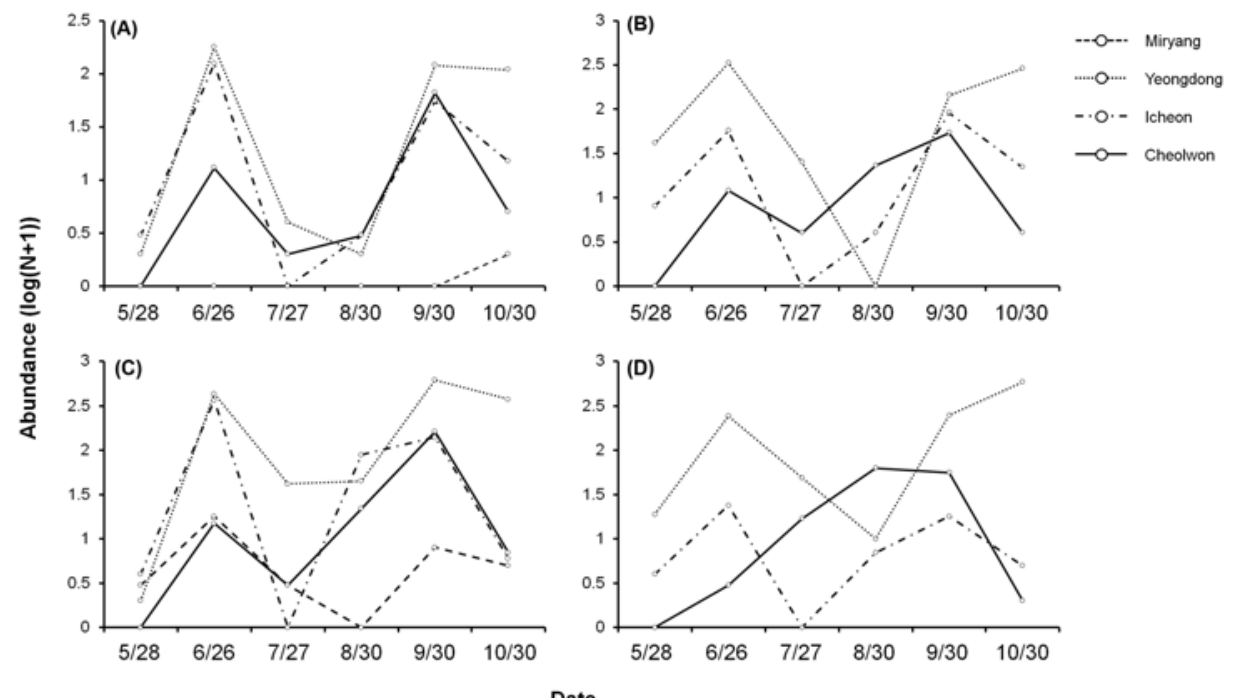

Fig. 3. Seasonality of 2 dominant species in each investigated region; Synuchus cycloderus in deciduous (A) and coniferous forest (B); Synuchus nitidus in deciduous (C) and coniferous forest (D).

bus koreanus koreanus was only collected from deciduous forest in Icheon-si (ID).

Analysis of similarity showed that there was no difference between forest stands (Global $R=-0.146, p=0.886$ ), while there was a significant difference among study regions (Global $\mathrm{R}=0.573, \mathrm{p}=0.019$ ). Non-metric multidimensional scaling and cluster analysis showed that 8 study sites diverged into 2 groups, Miryang (MC and MD) and other regions (Yeongdong, Icheon, and Cheolwon), at similarity level $36.1 \%$ (Fig. 4).

\section{Discussion}

Studying ground beetles between forest stands, i.e. con- 
(A)

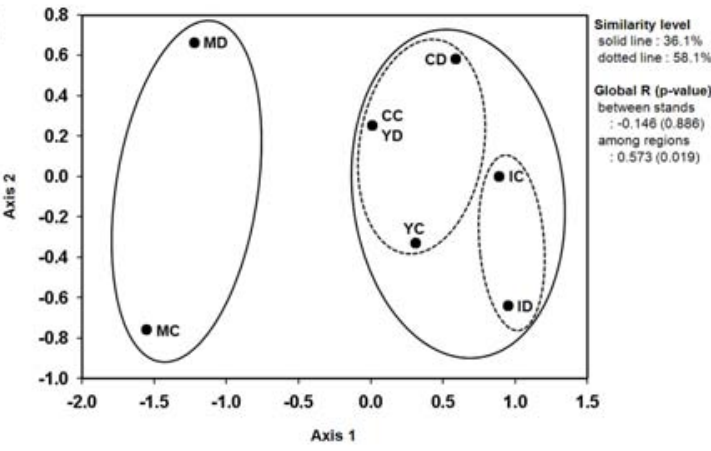

(B)

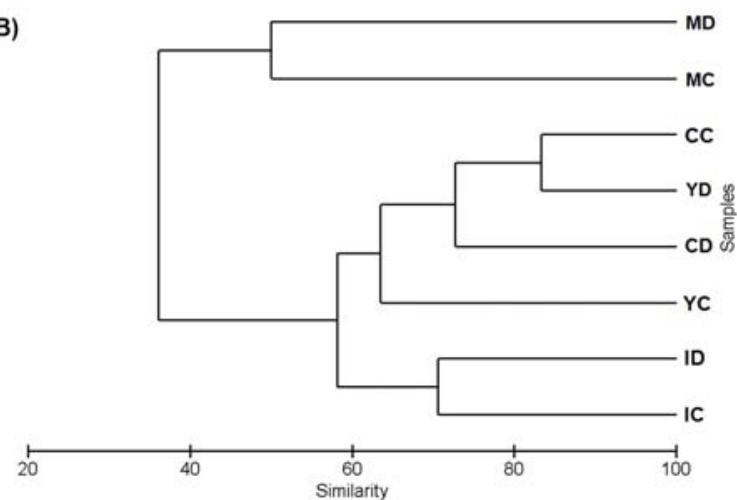

Fig. 4. NMDS ordination (A) and group averaging cluster analysis (B) based on Bray-Curtis similarity using presence-absence data of ground beetle assemblage among investigated regions and its forest stands.

iferous and deciduous forests, can provide some information for forestry due to bioindication characteristics of ground beetles. In Korea, Lee and Lee (1995) and Kubota et al. (2001) compared the ground beetle assemblage between forest stands. Lee and Lee (1995) showed a similar species composition of ground beetles between forest stands, but Kubota et al. (2001) showed some different for species composition and species richness of large-sized species as Carabinae. However, these previous studies could not represent the secondary forest in the agricultural landscapes, because study sites of Lee and Lee (1995) and Kubota et al. (2001) were located in mountainous areas, which are well conserved areas. In our study, on the other hands, forests at low altitudes and adjacent to agricultural areas as secondary forests showed a similar community structure of ground beetles between forest stands. This may general phenomenon in secondary forests, because secondary forests have been experienced by human activity frequently.
In general, habitat conditions, such as plants coverage, leaf litter, and soil humidity, may affect the distribution of ground beetles (Thiele 1977; Lövei and Sunderland 1996). In addition, altitude is one of major factors for community structure of ground beetles (Eyre et al. 2005; Hodkinson 2005), because forests in low altitudes are frequently disturbed by human activity, such as logging, fire, land conversions, and so on. Park (2010) also concluded that habitat management in the urban park may influence to the species composition and diversity of insects. In the results of our study, deciduous forest in Miryang is mainly composed of chestnuts (Castanea crenata var. dulcis), which indicates that this forest and ground flora has been managed by humans, such as spraying of pesticides and herbicides or clearing and thinning of vegetation. In addition, coniferous forest in Miryang showed lower soil humidity than other regions (Table 2). From these findings, low species richness and abundance of both coniferous and deciduous forest in Miryang can be explained, and thus, species composition was also different from other forests. On the other hands, many forest species of subfamily Carabinae and Pterostichinae did not collected in most our sampling sites compared to previous studies of mountainous area. Typical forest species such as A. k. koreanus and C. j. jankoreskii are mainly collected from the deciduous forest in Icheon-si. Low species richness of Carabinae species can be explained by forest characteristics of our study sites as young secondary forests, because forest history is also important to determine the distribution of forest species (Kubota et al. 2001; Riley and Browne 2011).

Though, Choi et al. (2004), Kang et al. (2009), and Do et al. (2011) reported the community structure of ground beetles in the habitats around levee of rice fields or hillocks in the agricultural landscapes of Korea, but there are still few studies on the ground beetle assemblages in the agricultural landscapes including secondary forests. In many countries, on the other hands, ground beetles have been studied for a long time in both crop and non-crop fields (Holland 2002), because ground beetles can be used as potential predators for reducing the pest populations (Kromp 1999; Holland 2002) and bioindicators for assessing the environmental status (Rainio and Niemelä 2003; Pearce and Venier 2006). For example, some carnivorous species as $S$. nitidus, which is generally dominant species in Korean 
forests in addition to Japanese forests (Kubota et al. 2000; Yeon et al. 2005), can be used as indicator for assessing chemical pollution in human-dominated environment, because their abundances are high in every forest along the urban-rural forest gradient as surrogate for the rate of human disturbances (Fujita et al. 2008).

\section{Conclusion}

In conclusion, ground beetles of forests in agricultural landscape showed a similar community structure between coniferous- and deciduous-dominant secondary forests, but different among regions due to different habitat conditions in each site. Although forest stands of secondary forests may not show a different community structure of ground beetle assemblages in our study, monitoring on the ground beetle fauna as well as other arthropods of secondary forests in agricultural landscapes are still important for biodiversity management and conservation, because forests adjacent to arable land are important for temporal refuges, habitats of reproduction, and overwintering sites for predatory arthropods, such as ground beetles, spiders and rove beetles.

\section{Acknowledgements}

This research was partially supported by Ministry of Environment (The effect of climate change on biogeographical subregions in Korea, NIBR no. 2009-01-008) and the Brain Korea 21 project.

\section{References}

Choi SW, Park M, Kim H. 2009. Differences in moth diversity in two types of forest patches in an agricultural landscape in Southern Korea. J Ecol Field Biol 32: 183-189.

Choi YC, Park HC, Kim JG, Sim HS, Kwon OS. 2004. Selection of indicator insects for the evaluation of agricultural environment. Korean J Appl Entomol 43: 267-273. (in Korean with English abstract)

Clarke KR, Gorley RN. 2006. PRIMER v6: User Manual/ Tutorial. PRIMER-E, Plymouth, UK.

Clarke KR, Warwick RM. 2001. Change in marine communities: an approach to statistical analysis and interpretation. 2nd ed. PRIMER-E, Plymouth, UK.

Do YN, Jeong KS, Lineman M, Kim JY, Kim HA, Joo GJ. 2011. Community changes in carabid beetles (Coleoptera: Carabidae) through ecological succession in abandoned paddy fields. J Ecol Field Biol 34: 269-278.

Eyre MD, Rushton SP, Luff ML, Telfer MG. 2005. Investigating the relationships between the distribution of british ground beethe species (Coleoptera, Carabidae) and temperature, precipitation and altitude. J Biogeogr 32: 973-983.

Fujita A, Maeto K, Kagawa Y, Ito N. 2008. Effects of forest fragmentation on species richness and composition of ground beetles (Coleoptera: Carabidae and Brachinidae) in urban landscapes. Entomological Science 11: 39-48.

Habu A. 1967. Fauna Japonica, Carabidae truncatipennes group (Insecta: Coleoptera). Biogeographical Society of Japan, Tokyo, Japan.

Habu A. 1973. Fauna Japonica, Carabidae: Harpalini (Insecta: Coleoptera). Keigaku Publishing Co. Ltd. Tokyo, Japan.

Habu A. 1978. Fauna Japonica, Carabidae: Platynini (Insecta: Coleoptera). Keigaku Publishing Co. Ltd. Tokyo, Japan.

Habu A. 1987. Classification of the Callistini of Japan (Coleoptera, Carabidae). Entomol Rev Japan 42: 1-36.

Hodkinson ID. 2005. Terrestrial insects along elevation gradients: species and community responses to altitude. Biol Rev Camb Philos Soc 80: 489-513.

Holland JM. 2002. The agroecology of carabid beetles. Intercept Ltd. Andover, Hampshire, UK.

Hong SK. 1999. Cause and consequence of landscape fragmentation and changing disturbance by socio-economic development in mountain landscape system of South Korea. J Environ Sci 11: 181-187.

Kagawa Y, Maeto K. 2009. Spatial population structure of the predatory ground beetle Carabus yaconinus (Coleoptera: Carabidae) in the mixed farmland-woodland landscape of Japan. European J Entomol 106: 385-391.

Kang BH, Lee JH, Park JK. 2009. The study on the characteristics of ground Beetle (Coleoptera: Carabidae) community for conservation of biodiversity in agricultural landscape. Korean J Environ Ecol 23: 545-552.

Katoh K, Sakai S, Takahashi T. 2009. Factors maintain species diversity in satoyama, a traditional agricultural landscape of Japan. Biol Conserv 142: 1930-1936.

Kromp B. 1999. Carabid beetles in sustainable agriculture: a review on pest control efficacy, cultivation impacts and enhancement. Agr Ecosyst Environ 74: 187-228.

Kubota K, Kim JK, Lee CY, Furuta K. 2001.Ground beetle fauna in Pinus densiflora forests in Yangyang-gun, Kangwon province, with a special reference to the outbreaks of the pine needle gall-midge (Thecodiplosis japonensis). J Korean For Soc 90: 632-642.

Kubota K, Lee CY, Kim JK. 2000. Invertebrates on the floor in Kangwon Province, Republic of Korea,with special reference to Japanese red pine forest infested with the pine needle gall-midge (Thecodiplosis japonensis). Rev Forest Culture 21: 137-146. (in Japanese with English abstract) 
Kwon YJ, Lee SM. 1984. Classification of the subfamily Carabinae from Korea (Coleoptera: Carabidae). Insecta Koreana, Series 4, Editorial Committee of Insecta Koreana, Seoul, Korea.

Lee HP, Lee GH. 1995. Species composition and seasonal abundance of ground beetles (Coleoptera: Carabidae) in three different types of forests. Entomol Res Bull 21: 84-90.

Lövei GL, Sunderland KD. 1996. Ecology and behavior of ground beetles (Coleoptera: Carabidae). Ann Rev Entomol 41: 231256.

McCune B, Grace JB. 2002. Analysis of ecological communities. Oregon, USA.

Park JK, Paik JC. 2001. Family Carabidae. Economic Insects of Korea 12. Ins. Koreana Suppl. 19, pp 170. (in Korean)

Park JK. 2004. Subfamily Carabinae in Korea (Coleoptera: Carabidae). Economic Insects of Korea 23. Ins. Koreana Suppl. pp. 30, 99.

Park JK. 2010. Insect fauna of urban green park in Daegu metropolitan city, Korea (II). Korean Journal of Turfgrass Science 24: 182-190. (in Korean with English abstract)

Pearce JL, Venier LA. 2006. The use of ground beetles (Coleoptera: Carabidae) and spiders (Araneae) as bioindicators of sustainable forest management: A review. Ecol Indic 6: 780-793.

Rainio J, Niemelä J. 2003. Ground beetles (Coleoptera: Carabidae) as bioindicators. Biodivers Conserv 12: 487-506.

Riley KN, Browne RA. 2011. Changes in ground beetle diversity and community composition in age structured forests (Coleoptera, Carabidae). In: Proceedings of asymposium honoring the careers of Ross and Joyce Bell and their contributions to scientific work. (Erwin T, ed). Burlington, Vermont, 12-15 June 2010. ZooKeys 147: 601-621.

Sotherton NW. 1985. The distribution and abundance of predatory Coleoptera overwintering in field boundaries. Ann Appl Biol 106: 17-21.

Takeuchi K, Brown RD, Wachitani I, Tsunekawa A, Yokohari M. 2003. Satoyama: The traditional rural landscape of Japan with 85 figures. Springer-Verlag, Tokyo.

Thiele HU. 1977. Carabid beetles in their environments: A study on habitat selection by adaptations in physiology and behavior. Springer-Verlag, Berlin.

Thomas MB, Wratten SD, Sotherton NW. 1991. Creation of 'Island'habitats in farmland to manipulate populations of beneficial arthropods: Predator densities and emigration. J Appl Ecol 28: 906-917.

Wallin H. 1986. Habitat choice of some field inhabiting carabid beetles (Coleoptera: Carabidae) studied by recapture of marked individuals. Ecol Entomol 11: 457-466.

Yeon HS, Park JK, Lee DW, Chung KM. 2005. Distribution of ground-beetles (Coleoptera: Carabidae) in Mt. Gabjangsan, Korea. Korean J Turfgrass Sci 19: 47-55. (in Korean with English abstract) 